\title{
Analisis Kepuasan Pengguna Layanan Google-Forms Sebagai Media Survey Online Menggunakan Delone \& Mclean
}

\author{
Ade Mubarok ${ }^{1}$, Noneng Tia Aprilia ${ }^{2}$, Sari Susanti ${ }^{3}$, Bambang Sukajie ${ }^{4}$, Chairil.M.Noor ${ }^{5}$ \\ 1,2,3,4,5 Universitas ARS
}

e-mail: 1job.dosen@gmail.com, ${ }^{2}$ n.tiaaprilia@gmail.com, ${ }^{3}$ sarisusanti95@gmail.com, 4bambangsukajie@gmail.com, ${ }^{5}$ chairil.noor@yahoo.com

\begin{abstract}
Abstrak
Kegiatan melakukan survei atau membagikan formulir, biasanya dihadapkan dengan banyaknya data yang harus diolah dengan berbagai cara atau metode, besarnya jumlah data yang didapatkan membuat pengolahan data memakan biaya dan waktu yang sangat lama. Dengan hadirnya layanan Google Forms diharapkan dapat memudahkan para pengguna yang sedang melakukan kegiatan survei online. Tujuan Penelitian ini untuk melihat hubungan antara variabelvariabel terhadap kepuasan pengguna layanan Google Forms di Kota Bandung menggunakan model DeLone \& McLean. Model DeLone \& McLean sendiri mempunyai enam variabel yaitu: Kualitas Sistem (System Quality), Kualitas Informasi (Information Quality), Kulalitas Layanan (Service Quality), Penggunaan (Use), Kepuasan Pengguna (User Satisfaction), dan Manfaat Bersih (Net Benefit), namun pada penelitian ini peneliti hanya menggunakan 5 variabel saja yaitu, Kualitas Sistem (System Quality), Kualitas Informasi (Information Quality), Kulalitas Layanan (Service Quality), Penggunaan (Use), dan Kepuasan Pengguna (User Satisfaction). Teknik pengambilan sampel yang digunakan adalah pendekatan convinience sampling. Hasil penelitian yang diperoleh adalah variabel Kualitas Sistem (System Quality) (X1), Kualitas Informasi (Information Quality) (X2), Kualitas Layanan (Service Quality) (X3), dan Penggunaan(Use) (X4) secara bersama-sama atau simultan berpengaruh terhadap Kepuasan Pengguna (User satisfaction) (Y).
\end{abstract}

Kata Kunci: Kepuasan Pengguna, Model DeLone \& McLean, Survey online

\begin{abstract}
The activity of conducting a survey or distributing forms is usually faced with the amount of data that must be processed in various ways or methods, the amount of data obtained makes processing data expensive and time-consuming. The presence of Google Forms is expected to make it easier for users who are conducting online survey activities. The purpose of this study was to look at the relationship between variables on Google Forms user satisfaction in the city of Bandung using the DeLone \& McLean model. The DeLone \& McLean Model itself has six variables: System Quality, Information Quality, Service Quality, Use, User Satisfaction, and Net Benefits Benefit. But in this study, the researchers only used 5 variables, namely, System Quality, Information Quality, Service Quality, Use, and User Satisfaction. The sampling technique used is convinience sampling approach. The results obtained are variable System Quality (X1), Information Quality (X2), Service Quality (X3), and Use (X4) together or simultaneous effect on User Satisfaction $(Y)$.
\end{abstract}

Keywords: User Satisfaction, DeLone \& McLean Model, Google Forms, Survey online

Pendahuluan

Maraknya kegiatan melakukan survei atau membagikan formulir, biasanya dihadapkan dengan banyaknya data yang harus diolah dengan berbagai cara atau metode. Besarnya jumlah data yang didapatkan, berbanding lurus dengan survei maupun formulir yang dibagikan dan didapatkan dari responden (Handayani et al., 2018). Hal tersebut tentu memakan waktu yang sangat lama. Oleh karena itu, Google menyediakan fitur yang dapat memudahkan penggunanya dalam membuat sebuah survei atau formulir (Handayani et al., 2018). 
Tujuannya agar akses informasi yang dibutuhkan pengguna dari responden menjadi lebih cepat dan secara otomatis tersimpan dalam layanan Google tersebut (Sorongan \& Hidayati, 2020). Salah satunya adalah layanan yang disediakan oleh Google yaitu Google Forms, Bebas kertas, analisis cepat, dan mudah didokumentasikan.

Google Forms atau yang disebut google formulir merupakan alat yang berguna untuk membantu kita dalam merencanakan acara, mengirim survei atau mengumpulkan informasi yang mudah dengan cara yang efisien, Google Forms juga aplikasi bagian dari google yang paling sering digunakan dalam pencarian data internet (Batubara, 2016). Pada aplikasi Google Forms kita juga bisa memanfaatkanya sebagai media berbasis online untuk kebutuhan kita khususnya dalam pembuatan kuesioner online, sehingga pengolahan data lebih terjamin dan terintegrasi dengan baik karena dengan memanfaatkan komputer sebagai pengolahan data elektronik (Handayani et al., 2018)

Kepuasan pengguna dalam pengunaan layanan Google-Forms mampu diukur dengan menggunakan teori yang dapat mengukur tingkat kepuasan pengguna terhadap suatu teknologi (Sukajie et al., 2019). Salah satunya adalah Model DeLone \& McLean, dipilih oleh peneliti dalam penelitian ini karena pada model ini menguji kualitas sistem, kualitas informasi, kualitas layanan, dan penggunaa terhadap tingkat kepuasan pengguna (Febriadi \& Nasution, 2017). Sementara model lain tidak memiliki kontruksi tersebut. Seperti model Technology Acceptance Model (TAM) yang meneliti persepsi pengguna terhadap teknologi dapat mempengaruhi sikapnya dalam penerimaan penggunaan teknologi, tetapi tidak bisa mengukur kepuasan pengguna terhadap sistem (Angelina et al., 2019)

Model Delone \& McLean digunakan untuk melakukan penelitian yang bertujuan untuk mengetahui faktor-faktor yang mempengaruhi kepuasan pengguna Layanan Google-Forms dengan menganalisis hubungan antara kualitas sistem dengan kepuasan pengguna, kualitas informasi dengan kepuasan pengguna, kualitas layanan terhadap pengguna dan penggunaan terhadap kepuasan pengguna (Wisudiawan, 2015).

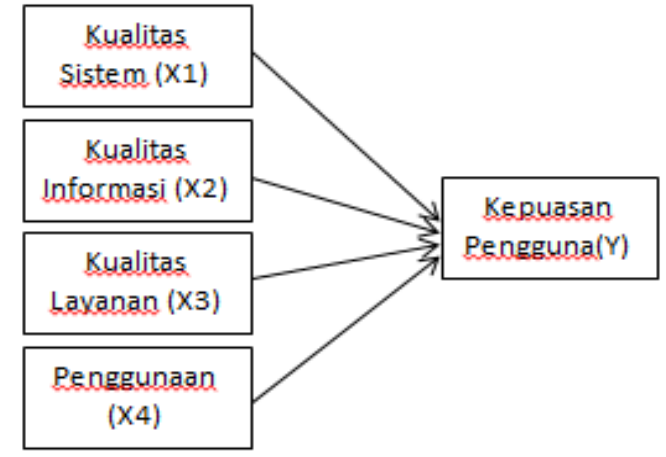

Gambar 1. Kerangka pemiikiran

Secara Skematis, kerangka berfikir dalam penelitian ini dapat digambarkan dalam gambar 1 .

Pada gambar 1 dapat dilihat kerangka berfikir dari penelitian ini sebagai berikut :

1. Variabel kualitas sistem (X1) akan berpengaruh signifikan positif terhadap variabel kepuasan pengguna $(Y)$.

2. Variabel kualitas informasi (X2) akan berpengaruh signifikan positif terhadap variabel kepuasan pengguna $(Y)$.

3. Variabel kualitas layanan (X3) akan berpengaruh signifikan positif terhadap variabel kepuasan pengguna $(Y)$.

4. Variabel penggunaan (X4) akan berpengaruh signifikan positif terhadap variabel kepuasan pengguna $(Y)$.

5. Variabel kualitas Sistem (X1), kualitas informasi (X2), kualitas layanan (X3), dan penggunaan (X4) secara bersamasama akan berpengaruh signifikan positif terhadap variabel kepuasan pengguna $(\mathrm{Y})$.

\section{Metode Penelitian}

Penelitian ini di awali dengan peneliti mengidentifikasi dan merumuskan permasalahan dengan bentuk pertanyaan yang dijawab pada maksud penelitian Hal-hal yang dipermasalahkan dalam penelitian adalah masalah dan peluang (opportunity), dimana pendefinisiannya harus jelas, baik dari segi keluasannya maupun kedalamannya (Sugiyono, 2017).

Peneliti membuat rumusan hipotesis atau dugaan sementara tentang fenomena yang akan diselidiki (Sapty Rahayu et al., 2018). Hipotesis ini berguna untuk membantu 
penulis menentukan jalan pikirannya agar mencapai hasil penelitiannya. Yang dihipotesiskan adalah pertanyaan yang ada pada perumusan masalah. Kemudian melakukan studi kepustakaan berdasarkan teori-teori yang sudah ada. Penulis mendapatkan teori dari berbagai jurnal dan buku yang terkait dengan penelitian yang dilakukan penulis. Peneliti juga menentukan sampel penelitian berdasarkan populasi. Sampel digunakan untuk mewakili dari keseluruhan populasi yang ada. Sampel yang digunakan oleh penulis adalah pengguna layanan Google Formss sebagai media survei online dan penyebaran kuesioner penelitian yang berada di wilayah Kota Bandung, sebanyak 100 orang.

Peneliti mengumpulkan data, sebagai bahan baku informasi yang harus dicari. Dalam hal ini penulis melakukan pengumpulan data melalui metode survei, dan penulis memperoleh data primer dengan cara menyebarkan kuesioner yang berisikan pertanyaan-pertanyaan kepada pengguna layanan Google Forms di Kota Bandung yang mengetahui dan menggunakan layanan Google Forms sebagai media survei online. Kuesioner diberikan kepada responden secara online, berbentuk link Google Forms dengan alamat kuesioner https://forms.gle/PDGiGraHGDttt8Rx7 untuk mendapatkan tanggapan dari responden terkait indikator-indikator dari masing-masing variabel Model DeLone \& McLean yang digunakan diantaranya kualitas sistem (system quality), kualitas informasi (information quality), kualitas layanan (service quality), penggunaan (use), dan kepuasan pengguna (user satisfiction).

Setelah data terkumpul, penulis mengelola dan menyajikan data sehingga informasi atau data yang tersaji lebih mudah diinterpretasikan dan analisis lebih lanjut. Hasil olahan dianalisis lebih lanjut dengan menggunakan alat-alat analisis yang sesuai dengan tujuan riset agar menghasilkan kajian yang cukup tajam, mendalam, dan luas. Hasil kajian ini dilengkapi dengan tafsirannya. Alatalat yang digunakan untuk melakukan analisis yaitu analisis deskriftif dan analisis statistik yaitu analisis korelasi dan analisis regresi linier berganda.

Hasil kajian ini dilengkapi dengan penjelasannya. Alat yang digunakan oleh peneliti adalah analisis deskriptif dan analisis statistik (Hermiyanty, Wandira Ayu Bertin, 2017). Setelah peneliti melakukan analisis data terhadap objek penelitian, maka peneliti membuat kesimpulan dan saran. Dimana kesimpulan yang ditarik berdasarkan acuan hipotesis yang telah dibuat sebelumnya. Saran yang disajikan oleh peneliti karena penelitian yang dilakukan memiliki keterbatasan-keterbatasan atau asumsiasumsi.

Berikut Gambar dari tahapan penelitian secara keseluruhan dapat dilihat pada gambar 2.:

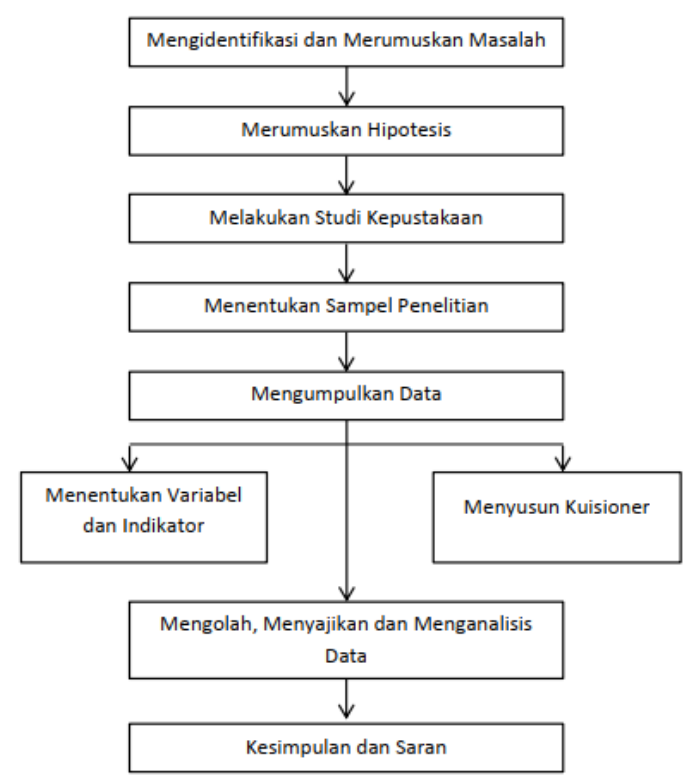

Gambar 2. Tahapan Penelitian

Populasi pada penelitian ini adalah pengguna layanan Google-Forms di kota bandung. Teknik yang digunakan untuk pengambilan sampel minimun adalah teknik pendekatan Non Probability Sampilng dengan menggunakan teknik convenience sampling. Metode ini dipilih oleh penulis karena jumlah populasi yang tidak diketahui sehingga peneliti memiliki kebebasan untuk memilih sampel yang paling cepat. Maka dari itu, dalam penentuan jumlah sampel penulis menggunakan rumus lameshow, yaitu:

Sumber : Stanley Lameshow

$$
n=\frac{Z_{1}-\alpha / 2 \mathrm{P}(1-\mathrm{P})}{d^{2}}
$$

\section{Keterangan:}

$\mathrm{n}=$ Jumlah Sampel

$z=$ Skor $z$ pada kepercayaan $95 \%=1,96$

$p=$ maksimal estimasi $=0,5$

$d=$ alpa $(0,10)$ atau sampling $=10 \%$ 
Menghitung Sampel Penelitian :

$\mathrm{n}=\frac{z^{2} 1-\alpha / 2 \mathrm{P}(1-\mathrm{P})}{d 2}$

$\mathrm{n}=\frac{1,96^{2} \cdot 0,5(1-0,5)}{0,1^{2}}$

$\mathrm{n}=\frac{3,8416 \cdot 0,25}{0,01}$

$n=96,04=100$

Sehingga jika berdasarkan rumus diatas maka $\mathrm{n}$ yang didapatkan adalah 96,04 $=100$ orang. Sehingga pada penelitian ini penulis harus mengambil data dari sampel setidaknya sekurang-kurangnya 100 orang.

Pengolahan hasil penelitian ini dimulai dengan melakukan uji coba instrumen dengan sample penelitian sebanyak 100 orang responden. Kuesioner berisikan pertanyaan berupa pernyataan yang tersusun dari variabel kualitas sistem (X1), kualitas informasi (X2), kualitas layanan $(X 3)$, penggunaan $(X 4)$, dan kepuasan pengguna $(Y)$ yang setiap indikatornya merupakan referensi dari penelitian sebelumnya.

Penelitian ini menggunakan data hasil penelitian yang diperoleh dari penyebaran kuesioner yang berupa google forms. Responden terbayak jika dilihat berdasarkan jenis kelamin adalah perempuan sebesar $51 \%$, sedangkan lakilaki sebesar $49 \%$. Sedangkan jika dilihat berdasarkan usia adalah usia $<20$ tahun sebesar $78 \%$, sedangkan usia 20-30 tahun sebesar $22 \%$

Tabel 1. Operasionalisasi Variabel

\begin{tabular}{|c|l|l|}
\hline Variabel & Indikator & \multicolumn{1}{c|}{ Deskripsi } \\
\hline & $\begin{array}{l}\text { Kemudahan } \\
\text { (Easy of } \\
\text { Kualitas } \\
\text { sistem } \\
\begin{array}{c}\text { (system } \\
\text { quality) }\end{array}\end{array}$ & $\begin{array}{l}\text { Tingkat kemudahan } \\
\text { penggunaan } \\
\text { layanan Google } \\
\text { Forms. }\end{array}$ \\
\cline { 2 - 3 } & $\begin{array}{l}\text { Waktu } \\
\text { Respon } \\
\text { (response } \\
\text { time) }\end{array}$ & $\begin{array}{l}\text { Tingkat ketepatan } \\
\text { waktu penyampaian } \\
\text { informasi pada } \\
\text { layanan Google } \\
\text { Forms. }\end{array}$ \\
\hline
\end{tabular}

\begin{tabular}{|c|c|c|}
\hline & $\begin{array}{l}\text { Keandalan } \\
\text { (reliability) }\end{array}$ & $\begin{array}{l}\text { Pengguna dapat } \\
\text { mengandalkan } \\
\text { layanan Google } \\
\text { Forms tanpa } \\
\text { mengkhawatirkan } \\
\text { kendala yang } \\
\text { mungkin terjadi } \\
\text { dalam system. }\end{array}$ \\
\hline \multirow{3}{*}{$\begin{array}{c}\text { Kualitas } \\
\text { informasi } \\
\text { (informat } \\
\text { ion } \\
\text { quality) }\end{array}$} & $\begin{array}{l}\text { Relevan } \\
\text { (relevance) }\end{array}$ & $\begin{array}{l}\text { Kesesuaian } \\
\text { informasi yang } \\
\text { didapatkan dari } \\
\text { layanan Google } \\
\text { Forms }\end{array}$ \\
\hline & $\begin{array}{l}\text { Akurat } \\
\text { (accuracy) }\end{array}$ & $\begin{array}{l}\text { Informasi yang } \\
\text { didapatkan dari } \\
\text { layanan Google } \\
\text { Forms tidak ambigu } \\
\text { dan bebas dari } \\
\text { kesalahan }\end{array}$ \\
\hline & $\begin{array}{l}\text { Lengkap } \\
\text { (completene } \\
\text { ss) }\end{array}$ & $\begin{array}{l}\text { Kelengkapan } \\
\text { informasi yang } \\
\text { diberikan layanan } \\
\text { Google Forms }\end{array}$ \\
\hline \multirow{2}{*}{$\begin{array}{l}\text { Kualitas } \\
\text { Layanan } \\
\text { (service } \\
\text { quality) }\end{array}$} & Resposif & $\begin{array}{l}\text { Kesesuaian } \\
\text { informasi yang } \\
\text { diperlukan secara } \\
\text { cepat dan tepat }\end{array}$ \\
\hline & Jaminan & $\begin{array}{l}\text { Keamanan yang } \\
\text { didapat pengguna } \\
\text { selama } \\
\text { menggunakan } \\
\text { layanan Google } \\
\text { Forms }\end{array}$ \\
\hline \multirow{2}{*}{$\begin{array}{l}\text { Penggun } \\
\text { aan } \\
\text { (use) }\end{array}$} & $\begin{array}{l}\text { Penggunaan } \\
\text { Sehari-hari } \\
\text { (daily used } \\
\text { time) }\end{array}$ & $\begin{array}{l}\text { Penggunaan } \\
\text { layanan Google } \\
\text { Forms dalam setiap } \\
\text { kebutuhan } \\
\text { penelitian }\end{array}$ \\
\hline & $\begin{array}{l}\text { Frekuensi } \\
\text { Penggunaan } \\
\text { (frequency of } \\
\text { use) }\end{array}$ & $\begin{array}{l}\text { Seberapa sering } \\
\text { penggunaan } \\
\text { layanan Google } \\
\text { Forms }\end{array}$ \\
\hline \multirow{3}{*}{$\begin{array}{l}\text { Kepuasa } \\
\text { n } \\
\text { Penggun } \\
\text { a (user } \\
\text { satisficati } \\
\text { on) }\end{array}$} & $\begin{array}{l}\text { Kepuasan } \\
\text { Informasi } \\
\text { (information } \\
\text { satisfaction) }\end{array}$ & $\begin{array}{l}\text { Tingkat kepuasan } \\
\text { informasi yang } \\
\text { pengguna dapatkan } \\
\text { melalui layanan } \\
\text { Google Forms }\end{array}$ \\
\hline & $\begin{array}{l}\text { Memenuhi } \\
\text { Harapan } \\
\text { (Expected } \\
\text { Quality) }\end{array}$ & $\begin{array}{l}\text { Informasi yang } \\
\text { didapatkan dari } \\
\text { layanan Google } \\
\text { Forms memenuhi } \\
\text { harapan pengguna }\end{array}$ \\
\hline & $\begin{array}{l}\text { Kepuasan } \\
\text { Menyeluruh } \\
\text { (overall } \\
\text { satisfaction) }\end{array}$ & $\begin{array}{l}\text { Tingkat kepuasan } \\
\text { secara keseluruhan } \\
\text { layanan Google } \\
\text { Forms }\end{array}$ \\
\hline
\end{tabular}

\section{Hasil dan Pembahasan}

Hasil dan pembahasan merupakan bagian yang membahas dan menjelaskan data yang terkumpul dari hasil penelitian yang meliputi uji instrumen: uji validitas dan 
uji reliabilitas, uji asumsi klasik: uji normalitas, uji autokolerasi, uji multikolinearitas, dan uji heteroskedastisitas, dan regresi linear berganda: uji hipotesis.

\section{Uji Instrumen}

\section{A. Uji validitas}

Uji validitas dilakukan yang dalam penelitian ini menggunakan rumus korelasi Bivariate pearson dimana data pertanyaan dikatakan valid jika memilki $r$ hitung $>r$ tabel. Nilai $r$ tabel pada penelitian ini adalah 0,195.

Tabel 2. Hasil Uji Validitas

\begin{tabular}{|c|c|c|}
\hline Kode & r hitung & Keterangan \\
\hline $\mathbf{X 1 . 1}$ & 0,493 & Valid \\
\hline $\mathbf{X 1 . 2}$ & 0,748 & Valid \\
\hline $\mathbf{X 1 . 3}$ & 0,760 & Valid \\
\hline $\mathbf{X 2 . 1}$ & 0,715 & Valid \\
\hline $\mathbf{X 2 . 2}$ & 0,844 & Valid \\
\hline $\mathbf{X 2 . 3}$ & 0,684 & Valid \\
\hline $\mathbf{X 3 . 1}$ & 0,875 & Valid \\
\hline $\mathbf{X 3 . 2}$ & 0,845 & Valid \\
\hline $\mathbf{X 4 . 1}$ & 0,789 & Valid \\
\hline $\mathbf{X 4 . 2}$ & 0,836 & Valid \\
\hline Y1.1 & 0,833 & Valid \\
\hline Y1.2 & 0,863 & Valid \\
\hline Y1.3 & 0,759 & Valid \\
\hline
\end{tabular}

\section{B. Uji Reliabilitas}

Uji reliabilitas menggunakan teknik Cronbach's alpha untuk menentukaan reliabilitas instrumen. Instrumen dikatakan reliabel jika nilai alpha $>$ nilai $r$ tabel.

Tabel 3. Hasil Uji Reliabilitas

\begin{tabular}{|c|c|c|c|}
\hline $\begin{array}{c}\text { No. } \\
\text { Item }\end{array}$ & $\begin{array}{c}r \\
\text { hitung }\end{array}$ & $\begin{array}{c}r \text { tabel } \\
5 \% \\
(100)\end{array}$ & Keterangan \\
\hline $\mathbf{X 1}$ & 0,404 & 0,195 & Reliabel \\
\hline $\mathbf{X 2}$ & 0,613 & 0,195 & Reliabel \\
\hline $\mathbf{X 3}$ & 0,647 & 0,195 & Reliabel \\
\hline $\mathbf{X 4}$ & 0,485 & 0,195 & Reliabel \\
\hline $\mathbf{Y}$ & 0,750 & 0,195 & Reliabel \\
\hline
\end{tabular}

\section{Uji Asumsi Klasik}

\section{A. Uji Normalitas}

Uji normalitas digunakan untuk menguji apakah data penelitian terdistribusi norma atau tidak. Data akan dinyatakan normal apabila titik-titik pada grafik menyabar disekitar garis dan mengikuti garis diagonal.

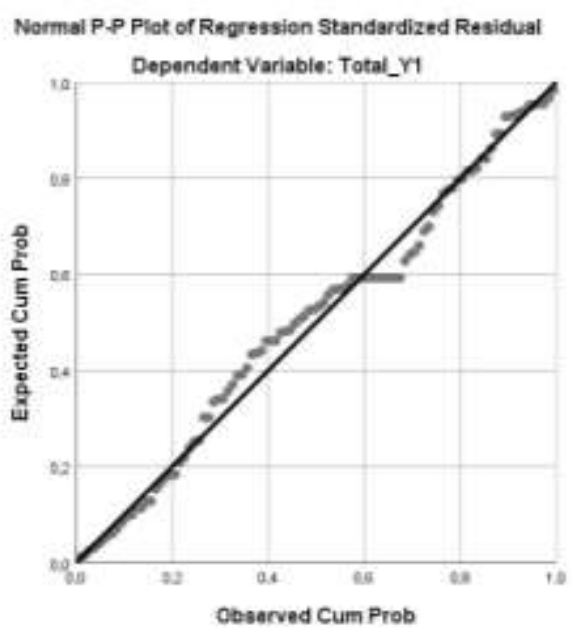

Gambar 3. Hasil Uji Normalitas

\section{B. Uji Autokolerasi}

Uji autokolerasi bertujuan untuk mencari tahu apakah suatu data pada periode tertentu berkolerasi dengan periode lainnya. Metode pengujian yang digunakan adalah uji Durbin-Watson (uji DW) dengan ketentuan jika nilai $1<\mathrm{DW}>3$ tidak terjadi autokolerasi.

Tabel 4. Hasil Uji Autokolerasi

\begin{tabular}{|l|c|c|c|}
\hline \multicolumn{4}{|c|}{ Model Summary } \\
\hline Model & $\mathrm{R}$ & $\begin{array}{c}\mathrm{R} \\
\text { Square }\end{array}$ & $\begin{array}{c}\text { Durbin- } \\
\text { Watson }\end{array}$ \\
\hline 1 &, $668^{\mathrm{a}}$ &, 447 & 2,269 \\
\hline \multicolumn{4}{|l}{ a. Predictors: (Constant), Total X4, Total X3, } \\
Total X2, Total X1 \\
\multicolumn{4}{|l}{ b. Dependent Variable: Total Y } \\
\hline
\end{tabular}

\section{Uji Multikolinearitas}

Tabel 5. Hasil Uji Multikolinearitas

\begin{tabular}{|c|c|c|c|}
\hline \multicolumn{4}{|c|}{ Coefficients $^{\mathrm{a}}$} \\
\hline \multirow{2}{*}{ Model } & \multirow{2}{*}{ Sig. } & \multicolumn{2}{|c|}{ Collinearity Statistics } \\
\hline & & Tolerance & VIF \\
\hline (Constant) & ,187 & & \\
\hline Total X1 & ,205 & ,645 & 1,551 \\
\hline Total X2 & ,298 & 676 & 1,480 \\
\hline Total X3 &, 002 & ,715 & 1,399 \\
\hline Total X4 &, 000 & 753 & 1,328 \\
\hline
\end{tabular}


Uji multikolinearitas digunakan untuk menguji ada tau tidaknya multikolinearitas yang dapat dilihat melalui Variance Inflation Factor (VIF). Nilai VIF $<10$ dan nilai tolerance $>0,1$ maka dapat disimpulkan tidak terjadi multikolinearitas.

\section{Uji Heteroskedastisitas}

Ketentuan dalam uji heteroskedastisitas ini apabila titik-titik menyebar diatas dan bawah angka 0 pada sumbu y sehingga dapat disimpulkan bahwa tidak terjadi masalah heteroskedastisitas.

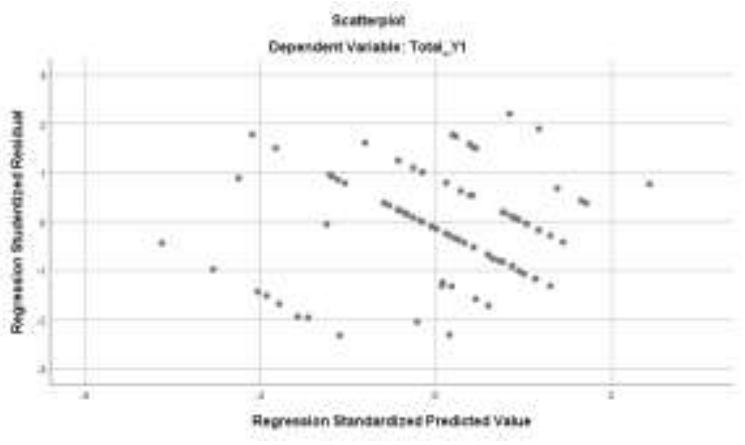

Gambar 3. Hasil Uji Heteroskedastisitas

Uji Hipotesis

\section{A. Uji T}

Uji T aatu uji parsial digunakan untuk menguji bagaimana pengaruh masingmasing variabel bebas terhadap variabel terikat. Nilai sig $<0,05$ atau $t$ hitung $<t$ tabel maka terdapat pengaruh variabel $\mathrm{X}$ terhadap variabel $\mathrm{Y}$.

Tabel 6 Hasil Uji T

\begin{tabular}{|l|r|r|}
\hline \multicolumn{3}{|c|}{ Coefficients $^{\mathbf{a}}$} \\
\hline & & \multicolumn{1}{|c|}{ Sig. } \\
\hline Model & $\mathrm{t}$ &, 187 \\
\hline Constant) & 1,329 &, 205 \\
\hline Total X1 & 1,277 &, 298 \\
\hline Total X2 & 1,046 &, 002 \\
\hline Total X3 & 3,170 &, 000 \\
\hline Total X4 & 4,150 & \\
\hline
\end{tabular}

\section{B. Uji F}

Uji F digunakan untuk menguji bagai mana pengaruh semua variabel bebas secara bersama-sama terhadap variabel terkait. Nilai sig $<0,05$ atau $f$ hitung $>f$ tabel maka terdapat pengaruh variabel $X$ terhadap variabel $\mathrm{Y}$.

Tabel 7. Hasil Uji F

\begin{tabular}{|l|c|c|}
\hline \multicolumn{3}{|c|}{ ANOVA $^{\mathrm{a}}$} \\
\hline Model & $\mathrm{F}$ & Sig. \\
\hline Regression & 19,162 &, $000^{\mathrm{b}}$ \\
\hline Residual & & \\
\hline Total & & \\
\hline a. Dependent Variable: Total Y \\
\hline \begin{tabular}{l} 
b. Predictors: (Constant), Total X4, \\
Total X3, Total X2, Total X1 \\
\hline
\end{tabular}
\end{tabular}

\section{Uji Koefisien Determinasi}

Uji keofisien determinasi bertujuan untuk mengetahui besarnya sumbangan atau kontribusi dari variabel bebas terhadap variabel terkait.

Tabel 8. Persentase hasil uji koefisien determinasi

\begin{tabular}{|c|c|c|}
\hline No. & $\begin{array}{c}\text { Nama } \\
\text { Variabel }\end{array}$ & Presentase \\
\hline 1. & $\mathrm{X} 1(\mathrm{KS})$ & $17,4 \%$ \\
\hline 2. & $\mathrm{X} 2(\mathrm{KI})$ & $15,5 \%$ \\
\hline 3. & $\mathrm{X} 3(\mathrm{KL})$ & $28 \%$ \\
\hline 4. & $\mathrm{X} 4(\mathrm{P})$ & $31,9 \%$ \\
\hline
\end{tabular}

\section{Kesimpulan}

Dari hasil analisis dengan menggunakan model DeLone \& McLean maka dapat dibuat kesimpulan:

1. Variabel Kualitas Sistem (System Quality) secara parsial tidak memiliki pengaruh positif signifikan terhadap Kepuasan Pengguna (User satisfaction).

2. Variabel Kualitas Informasi (Information Quality) secara parsial tidak memiliki pengaruh positif signifikan terhadap Kepuasan Pengguna (User satisfaction).

3. Variabel Kualitas Layanan (Service Quality) secara parsial memiliki pengaruh positif signifikan terhadap Kepuasan Pengguna (User satisfaction).

4. Variabel Pengunaan (Use) secara parsial memiliki pengaruh positif signifikan terhadap Kepuasan Pengguna (User satisfaction). 
5. Variabel Kualitas Sistem (System Quality) (X1), Kualitas Informasi (Information Quality) (X2), Kualitas Layanan (Service Quality) (X3), dan Penggunaan (Use) (X4) secara bersama-sama atau simultan berpengaruh terhadap Kepuasan Pengguna (User satisfaction) $(\mathrm{Y})$.

\section{Referensi}

Angelina, R. J., Hermawan, A., \& Suroso, A. I. (2019). Analyzing E-Commerce Success using DeLone and McLean Model. Journal of Information Systems Engineering and Business Intelligence, $5(2)$, 156. https://doi.org/10.20473/jisebi.5.2.156162

Batubara, H. H. (2016). Di Prodi Pgmi Uniska Muhammad Arsyad Al Banjari. Universitas Islam Kalimantan MAB, 8(1), 40-50.

Febriadi, B., \& Nasution, N. (2017). Sosialisasi Dan Pelatihan Aplikasi Google Form Sebagai Kuisioner Online Untuk Meningkatkan Kualitas Pelayanan. INOVTEK Polbeng - Seri Informatika, 2(1), 68. https://doi.org/10.35314/isi.v2i1.119

Handayani, I., Aini, Q., Cholisoh, N., \& Agustina, I. I. (2018). Pemanfaatan Google Form Sebagai Pendaftaran TOEFL (Test Of English as a Foreign Language) Secara Online. Jurnal Teknoinfo, 12(2), 55. https://doi.org/10.33365/jti.v12i2.73
Hermiyanty, Wandira Ayu Bertin, D. S. (2017). Technology Science and Engineering Journal. Journal of Chemical Information and Modeling, 1(9), $\quad 1-58$. https://doi.org/10.1017/CBO978110741 5324.004

Sapty Rahayu, F., Apriliyanto, R., \& Sigit Purnomo Wuryo Putro, Y. (2018). Analisis Kesuksesan Sistem Informasi Kemahasiswaan (SIKMA) dengan Pendekatan Model DeLone dan McLean. Indonesian Journal of Information Systems, 1(1), 34-46. https://doi.org/10.24002/ijis.v1i1.1704

Sorongan, E., \& Hidayati, Q. (2020). Integration of eucs variables into delone and mclean models for e-government evaluation: Conceptual models. Register: Jurnal Ilmiah Teknologi Sistem Informasi, 6(1), 33. https://doi.org/10.26594/register.v6i1.1 608

Sugiyono. (2017). Metode Penelitian (25th ed.). CV. ALFABETA.

Sukajie, B., Laksono, F. A., Mubarok, A., Susanti, S., \& Kurniawan, A. (2019). Analisis Kepuasan Pengguna Youtube Sebagai Media Pendidikan Menggunakan Model DeLone dan McLean. Jurnal Responsif, 1(1), 46-52.

Wisudiawan, G. A. A. (2015). Analisis faktor kesuksesan sistem informasi menggunakan model delone and mclean. Jurnal IImiah Teknologi Informasi Terapan, 2(1), 55-59. 